\title{
Is British physical anthropology dying?
}

Bernard Campbell, Adjunct Professor of Anthropology, University of California, Los Angeles, argues that teaching and research in physical anthropology should be developed and expanded in the $U K$.

RESEARCH and teaching in the most fundamental branch of the science of physical anthropology is today almost extinct in Great Britain. Senior positions are no longer available, and almost all the talented scholars in the field have moved to the US or Canada. Human palaeontology, as a key part of the anthropological sciences, is taught by permanent staff in the Anthropology Department of only one University: Cambridge. While it is also taught in a limited way in at least five anatomy departments of medical schools, this teaching is generally in the context of human anatomical studies and is therefore not in its most appropriate milieu, namely, the knowledge of human society and culture, and of the evolutionary paradigm.

This is a near disaster. Physical anthropology, concerned as it is with man's biology, is the study of the most fundamental aspects of human nature. While it can be said to date from J. F. Blumenbach (1752-1840) (who classified races and made a collection of human skulls) it came of age and gained its central paradigm with the publication of Darwin's Origin of Species (1859).

Today, physical or biological anthropologists study Man as a product of natural selection and try to understand human variability in the light of evolution. The biology of Man has branched into many sub-disciplines, including comparative anatomy and comparative physiology, which are at the centre of human biology; the study of human growth and variability; genetics; primate palaeontology; primate behaviour; human ecology; and many others. Physical anthropology is therefore necessarily disparate in its specialisations.

At University College, London, for example, staff are presently doing research into the systematics of the Galagidae, the genetics of marriage in modern Britain, the serological genetics and nutrition of Carib populations, the genetics of Ethiopian baboons, and the strength and structure of bone. Many of these specialisations lean heavily on developments in related sciences, especially human genetics and physiology, and zoology. Sometimes it seems that these diverse specialists would be better placed in other departments. Yet research into human blood-groups was immensely stimulated by anthropological considerations and data, and studies of primate behaviour were given a new focus by anthropologists S. L. Washburn and I. DeVore. Anthropologists have both received from, and given to, related disciplines, and their central interest in 'the proper study of mankind' energises and directs their research.

In the early years of this century Karl Pearson, G. M. Morant and others, worked painstakingly with calipers and measuring tapes to produce a vast amount of quantitative data about the skeleton of modern man. They also studied the rather limited fossil record in the same way. The method produced meagre results and in the 1940s Fisher's population genetics and the new research on the ABO blood groups developed as a far more powerful tool with which the nature of racial differences and at least recent human prehistory might be uncovered. The dimension of time proved elusive, however, and while the genetical aspects of Man's place in nature probably hold pride of place today in most departments of physical anthropology throughout the world, these studies do not and cannot develop that central explanatory paradigm, which alone can hold physical anthropology together as a science.

The fossil evidence for human evolution and its interpre- tation into a more complete understanding of Man's past has become alive again with the development of a functional approach to anatomical analysis. S. L. Washburn was probably the first to insist on its importance (circa 1950) and others followed. My book Human Evolution (1966) was an early attempt to make such a functional integration. The bones came to life, and behavioural speculation followed. As a result physical anthropology came closer to its sister discipline, prehistoric archaeology: together they constitute the science of evolutionary anthropology or palaeoanthropology sensu lato. Palaeoanthropologists are not today expected to be outstanding scholars in both human palaeontology and prehistoric archaeology, but they are expected to be very much aware of the value of each science and its vital importance in understanding the evolution of human nature. The interdisciplinary study of the evolution of man which also includes vertebrate palaeontology, palaeoecology, and palaeogeography, is necessarily the main stem from which all the sub-disciplines of physical anthropology mentioned above are nourished. In spite of the complexity of anthropology, an anthropologist must necessarily be a generalist as well as a specialist: he must specialise in the light of his knowledge of mankind's whole adaptive strategy.

Human palaeontologists must, therefore. more than ever before, rub shoulders with social and cultural anthropologists and archaeologists: and at the same time they must see man at all time; - not as a creature apart from nature, but as a very remarkable animal. It follows that although the anatomy departments have housed and nourished human palaeontologists for three to four generations in the UK (since the time of Sir Grafton Elliot Smith and Sir Arthur Keith), they can no longer remain the primary resource for this subject.

At a recent inaugural meeting in London, the L. S. B. Leakey Foundation presented its goal of further study into "Man's origin, behaviour and survival". and plans to support students and research projects in areas which reflect this holistic approach to the study of man. What is needed in Britain is a Department of Physical Anthropology with the prestige, money and manpower to bring back to Britain some of those palaeoanthropologists who have left. Britain needs a university with the will and the resources to bring to life the main stem of all anthropology-the study of human evolution. Man has been part of Nature-as a hunter and gatherer-for $99 \%$ of the approximately 2 million years of his existence on earth. Man is a product of his prehistory, and our understanding of our present predicament depends squarely on our knowledge of our own past.

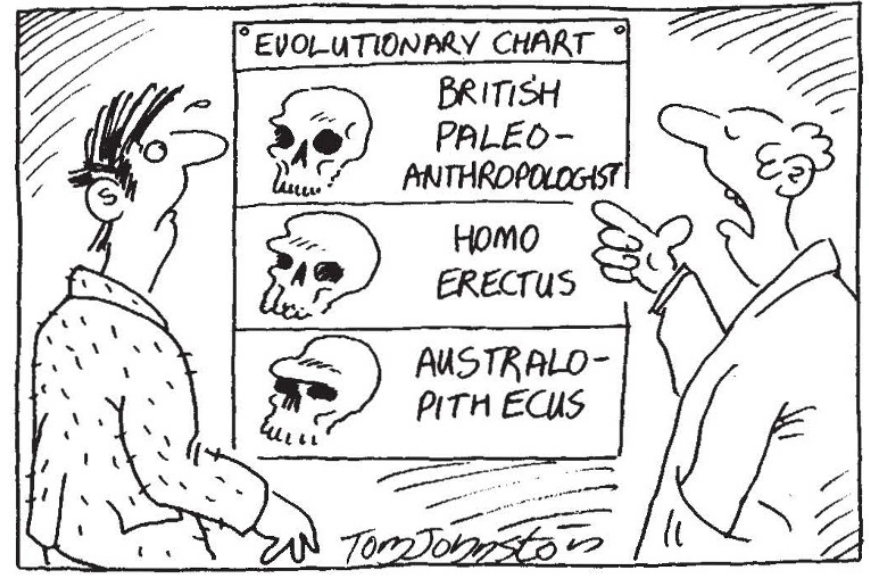

"Of course, they're extinct now too!" 